\title{
Weak Hydrogen Bonds in Some Six- and Five-atom Interactions: An AIM Topological Analysis
}

\author{
Francisco Sánchez-Viesca*, Fernando Cortés, Reina Gómez, Martha Berros
}

Faculty of Chemistry, Graduate Division, National Autonomous University of Mexico. México, D.F., 04510, México

\begin{abstract}
In the ${ }^{1} \mathrm{H}$ NMR spectra of several thiazole derivatives we have found that some of them present downfield shifts (to higher frequency). These $\Delta \partial$ can be attributed, in a broad sense, to intramolecular hydrogen bonding. However, we present an AIM study that shows there are two types of atomic interactions in these compounds: some originate bond critical points, but others do not. It is interesting to note that intramolecular hydrogen bonds were formed when a six-member ring and an electronegative atom, such as oxygen or chlorine, were involved. However, interactions involving five-member rings and a nitrogen atom as electron donor showed only three of the six required theoretical properties for hydrogen bonding. These special interactions can be considered as very weak hydrogen bonds. Nevertheless, both types of atomic interactions caused similar downfield shifts in the ${ }^{1} \mathrm{H}$ NMR spectra. Thus, this study reveals differences in the nature of the atomic interactions that gave rise to downfield shifts in the ${ }^{1} \mathrm{H}$ NMR spectra.
\end{abstract}

Keywords Intramolecular hydrogen bonding, electron donors, Atomic-ring interactions, Structural analysis, Physical Chemistry

\section{Introduction}

Among the so-called non-conventional hydrogen bonds[1], there is the $\mathrm{R}-\mathrm{C}-\mathrm{H}---\mathrm{X}$ group $(\mathrm{X}=\mathrm{O}, \mathrm{Cl}$ and $\mathrm{N})$. These are weak hydrogen bonds[2],[3], since the energy of these secondary bonds is smaller due to the lower acidity of the involved hydrogen atoms.

In a previous paper[4], we discussed the ${ }^{1} \mathrm{H}$ NMR spectra of several poly-substituted 4-aryl thiazoles. Our study found two groups of compounds, having or not, the possibility to form $\mathrm{C}-\mathrm{H}---\mathrm{X}$ hydrogen bonds, $\mathrm{X}$ being $\mathrm{O}, \mathrm{Cl}$ or $\mathrm{N}$. The formation or not of these hydrogen bonds gives rise to preferred conformations (rotamers). Figure 1.

In this study, three representative compounds were chosen: 2-methyl-4-(2,4,5-trimethoxyphenyl) thiazole, I, which presents downfield shifts in the ${ }^{1} \mathrm{H}$ NMR spectrum ( $\left.\mathrm{CDCl}_{3}, 300 \mathrm{MHz}\right) ;$ 2-methyl-4-(2-methyl-4,5- dimethoxyphenyl) thiazole, II, with normal chemical shifts; and 2-methyl-4-(2-chloro-4,5-dimethoxyphenyl) thiazole, III, which presents smaller downfield shifts than compound I. The $\partial$ values are given in the formulas and we can observe significant $\Delta \partial$ for $\mathrm{H}-6$ (benzene ring) and for the thiazolic proton in compounds I and III, as compared to the 2-methylaryl compound II. These downfield shifts (to higher frequency) were ascribed to hydrogen bonding.

* Corresponding author:

franviesca@yahoo.com (Francisco Sánchez-Viesca)

Published online at http://journal.sapub.org/chemistry

Copyright (C) 2012 Scientific \& Academic Publishing. All Rights Reserved
However, we wanted to confirm, or not, the existence of hydrogen bonding suggested by the experimental NMR chemical shifts results, by a theoretical study of the electronic density of the intramolecular hydrogen bond network of these molecules, as well by H-bond parameters in terms of the bond distances and the appropriate bond angles and compared to other work. The hydrogen bond strengths were calculated by rotating about the $\mathrm{C}-\mathrm{C}$ bond between the rings, breaking the $\mathrm{H}$ bonds. Frequency calculations were done to insure the structures are minima.

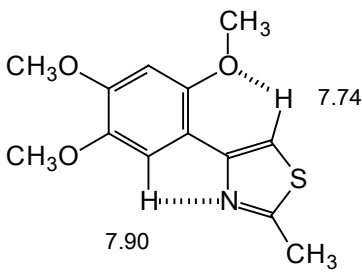<smiles>COc1cc(C)c(-c2csc(C)n2)c([18OH])c1</smiles>

I II

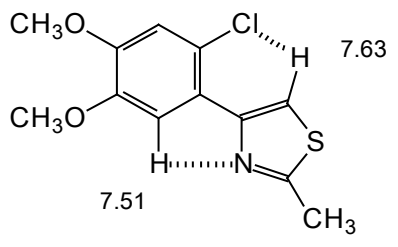

III

Figure 1. Hydrogen bonds suggested by ${ }^{1} \mathrm{H}$ NMR study 
Structures of three molecules were optimized at the B3LYP/6-311G $++(d, p)$ level of theory[5-7], with the Gaussian 03 software[8]. Revision C.02 of Gaussian was used to perform the geometry optimizations and produce the wave function files that the AIM analysis needs, AIM 2000 code[9]. The calculations were made in the SGIOrigin 2000/32 supercomputer, at DGSCA-UNAM.

\section{Results and Discussion}

In order to simplify the calculations, a hydrogen atom replaced the methyl group at the thiazole ring. This change is valid since it does not affect the possibility of hydrogen bond formation. In order to facilitate comparisons, equivalent Arabic numerals are used for these related molecules and the drawing is in accord with the molecular graphs obtained (Figure 2). The structures of molecules 1, 2 and 3 were calculated and a search for bond critical points (BCP) of the $\mathrm{C}-\mathrm{H}---\mathrm{O}, \mathrm{C}-\mathrm{H}---\mathrm{Cl}$ and $\mathrm{C}-\mathrm{H}---\mathrm{N}$ contacts was conducted. In Atoms in Molecules theory, the existence of a bond path between the hydrogen bond donor and the hydrogen bond acceptor, as well as a bond critical point, are sufficient criteria to establish bond existence[10]. The molecular structure can be obtained in a molecular graph showing all the bond paths and bond critical points.

The existence of a C-H---O hydrogen bond in the trimethoxyphenyl thiazole 1 is shown in Figure 2. A six member ring is formed and the ring critical point can be observed. The methyldimethoxyphenyl thiazole, 2, presents classical bonding, with no hydrogen bond, as was postulated in[4] for compound II.

Molecule 3, the chlorodimethoxyphenyl thiazole, shows a $\mathrm{C}-\mathrm{H}---\mathrm{Cl}$ hydrogen bond, similarly to molecule 1 .

However, here comes a difference. A possible C-H---N hydrogen bond involving $\mathrm{H} 7$ was searched in molecules 1 and 3, but it was not found. With molecule 1, the system was rotated to obtain a zero N-C-C-C-H7 dihedral angle, a planar system, but the $\mathrm{N}---\mathrm{H} 7$ critical point was not found (although the change was only $0.5^{\circ}$ ). A similar procedure with biphenyl has been described by Cioslowsky[11]. Therefore, the level of theory was improved to MP2-6-311++G(2d,2p) but the critical point was missing.

Nevertheless, the preferred rotamers $(1,2$ and 3$)$ are in accord with those previously proposed[4] for compounds I, II and III, and the interaction between the nitrogen atom and $\mathrm{H} 7$ has been registered in the ${ }^{1} \mathrm{H}$ NMR spectra of I and III as $\Delta \partial$ (downfield shifts).

Molecule 3 shows a $26.8^{\circ}$ dihedral angle; however, a single-crystal X-Ray diffraction study of the related compound III shows a planar structure[12]. This resembles the biphenyl dihedral angle variations: $26.8^{\circ}$ in crystalline state, $19-32^{\circ}$ in solution, and $44^{\circ}$ in gas phase[13]. Popelier studied extensively C-H---O hydrogen bonds and, based on Atoms in Molecules Quantum Theory (AIM formalism), established a series of charge-density-based criteria for hydrogen bonding identification purposes[14],[15]. His work has been cited many times, $\mathrm{C}-\mathrm{H}---\mathrm{O}$ hydrogen bonds have gained acceptance and have explained conformational stability in some systems[16].

The hydrogen bond criteria are:

1) The existence of a bond path, containing a bond critical point (BCP) between the donor hydrogen nucleus and the acceptor.

2) The second necessary condition involves a local property, namely, the electronic charge density evaluated at the bond critical point. The range of $\rho$ values must be between 0.002 a.u. and 0.035 a.u.

3) The value of the Laplacian, Bader[17], of the charge density at the BCP must be between 0.024 a.u. and 0.139 a.u. It is crucial that $\nabla^{2} \rho$ is positive.

4) Loss of charge of the hydrogen atom. This is computed by subtracting the electronic population of the hydrogen in the free state from the associate state.

5) Must be energetic destabilization of the hydrogen atom. This effect is measured by $\Delta \mathrm{E}(\mathrm{H})$.

6) Decrease of the hydrogen atom's volume.

In this study, the bond critical point characteristics are summarized for comparison in Table 1. The atomic properties of $\mathrm{H} 7, \mathrm{H} 14$ and $\mathrm{H} 15$ in structures 1, 2 and 3 can be found in Table 2. The C-H14---O hydrogen bond satisfies all the above criteria. It presents an adequate topology and the charge density at the H14---O bond critical point is 0.016 a.u. and in molecule 3 the charge density at the $\mathrm{H} 14---\mathrm{Cl} \mathrm{BCP}$ is
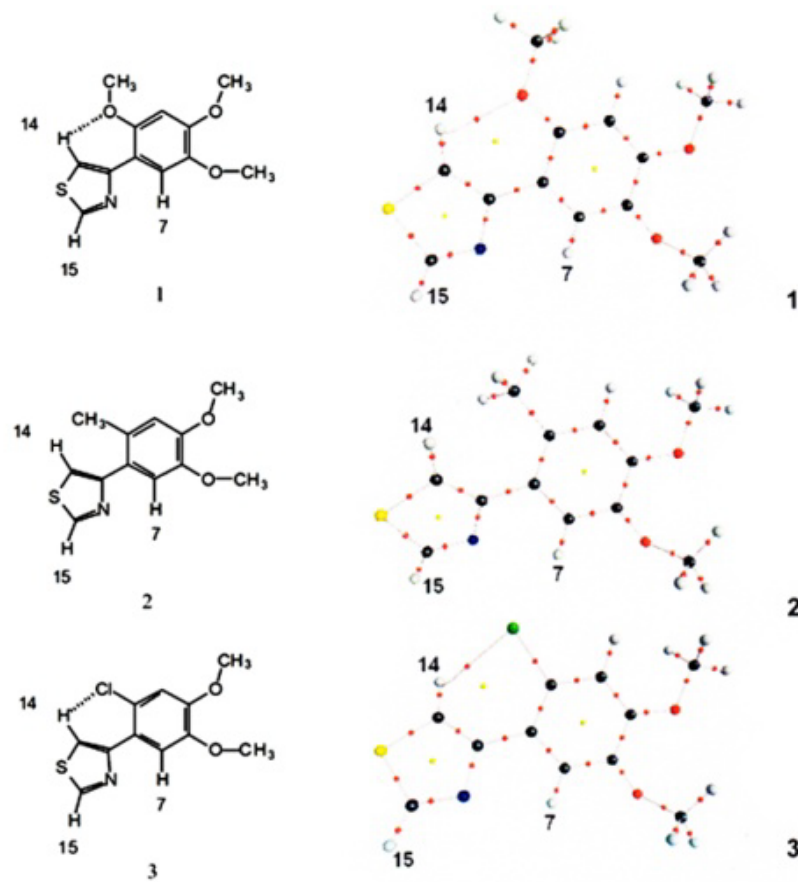

Figure 2. Molecular graphics of structures 1, 2 and 3, showing the critical points

0.012 a.u. Both values are in the middle of the above-cited range.

In hydrogen-bonded molecules 1 and 3, the $\mathrm{H} 14$ electronic population decreases 0.031 and 0.006 e, respectively, in comparison to molecule 2 . The electronic destabilization of 
$\mathrm{H} 14$ is 5.56 and $1.32 \mathrm{kcal} / \mathrm{mol}$ and the $\mathrm{H} 14$ volume decreases 3.3 and 1.1 a.u., respectively.

Table 1. Bond-critical-point Characteristics

\begin{tabular}{|c|c|c|}
\hline \multicolumn{3}{|c|}{$\rho$, Electronic Charge Density in a.u. } \\
$\nabla^{2} \rho, \quad$ Laplacian of the Charge Density at the BCP \\
\hline & $\rho$ & $\nabla^{2} \rho$ \\
\hline Molecule 1 & & \\
\hline C-H14 & 0.2968 & -1.1461 \\
H14-O & 0.0166 & 0.0663 \\
C-H7 & 0.2942 & -1.1228 \\
C-H15 & 0.2944 & -1.1336 \\
\hline Molecule 2 & & \\
\hline C-H14 & 0.2940 & -1.1210 \\
C-H7 & 0.2932 & -1.1142 \\
C-H15 & 0.2945 & -1.1354 \\
\hline Molecule 3 & & \\
\hline C-H14 & 0.2924 & -1.1039 \\
H14-Cl & 0.0122 & 0.0478 \\
C-H7 & 0.2907 & -1.0794 \\
C-H15 & 0.2916 & -1.0971 \\
\hline
\end{tabular}

Table 2. Atomic Properties Values

\begin{tabular}{|c|c|c|c|}
\hline \multicolumn{3}{|c|}{ N, Electronic Population } \\
E, Total Energy of the Atom \\
v, Atomic Volume, in a.u. \\
\hline & $\mathrm{N}(\mathrm{H})$ & $\mathrm{E}(\mathrm{H})$ & $\mathrm{v}(\mathrm{H})$ \\
\hline Molecule 1 & & & \\
\hline H7 & 0.934 & -0.60513 & 43.391 \\
H14 & 0.913 & -0.59744 & 41.066 \\
H15 & 0.938 & -0.60324 & 46.822 \\
\hline Molecule 2 & & & \\
\hline H7 & 0.946 & -0.60925 & 44.587 \\
H14 & 0.944 & -0.60630 & 44.358 \\
H15 & 0.935 & -0.60181 & 46.589 \\
\hline Molecule 3 & & & \\
\hline H7 & 0.952 & -0.61152 & 43.800 \\
H14 & 0.938 & -0.60419 & 43.265 \\
H15 & 0.950 & -0.60778 & 46.430 \\
\hline
\end{tabular}

On the other hand, H15 in molecules 1 and 3 (as can be seen in Tables 1 and 2) shows an increased population $(0.003$ and $0.015 \mathrm{e}$ ) and an electronic stabilization, 0.88 and 3.7 $\mathrm{kcal} / \mathrm{mol}$, respectively. Concerning H15 volume, in molecule 1 there is a 0.233 a.u. increase, whereas in molecule 3 a 0.159 a.u. decrease is observed. This difference is probably due to the chlorine atom influence in molecule 3 .

Concerning $\mathrm{H} 7$, in molecule 1 the electronic population loses $0.012 \mathrm{e}$, but in molecule 3 gains $0.006 \mathrm{e}$ (compared to molecule 2 in both cases). $\mathrm{H} 7$ is destabilized in 1 by 2.59 $\mathrm{kcal} / \mathrm{mol}$ and stabilized in 3 by $1.42 \mathrm{kcal} / \mathrm{mol}$. In both molecules (1 and 3) H7 decreases in volume, 1.196 and 0.787 a.u., respectively. The condition of $\mathrm{H} 7$ is interesting since although the first three Popelier's criteria does not apply to a C-H7---N secondary bond, there is a decrease in electronic population as well as in volume, as expected for this interaction.
The special interaction $\mathrm{H} 7---\mathrm{N}$ is in accord with the downfield shifts observed in the 1H NMR spectra[4] of compounds I and III, but it is not properly a hydrogen bond.

Other calculations were also made, such as H-bond parameters in terms of the bond distances and the appropriate bond angles, and were compared to other work.

The H(thiazolic)---O distance in compound I is $2.24 \AA$. Experimentally, the interaction $\mathrm{C}-\mathrm{H}---\mathrm{O}$ is within the 2.04-2.39 Å range[18].

The calculated distance for $\mathrm{H}$ (thiazole)--- $\mathrm{Cl}$ in the chloroaryl thiazole III is $2.51 \AA$. This theoretical result is in agreement with the existence of a weak hydrogen bond, considering that 2.57-2.94 $\AA$ values, obtained by X-Ray Crystallography, are reported[18]. The calculated H6---N distances for structures I and III are 2.34 and $2.28 \AA$. These values are even shorter than reported values $(2.52-2.72 \AA)$ for significant hydrogen bond formation[18].

Other important geometric parameter is the bond angle $\mathrm{C}-\mathrm{H}---\mathrm{X}(\mathrm{X}=\mathrm{O}, \mathrm{Cl}$ and $\mathrm{N})$. In the trimethoxyphenyl thiazole, $\mathrm{I}$, the $\mathrm{C}-\mathrm{H}$ (thiazolic)---O angle is $109.68^{\circ}$ and the $\mathrm{C}-\mathrm{H}---\mathrm{N}$ angle is $102.63^{\circ}$. Desiraju and Steiner[3] report that the $\mathrm{C}-\mathrm{H}---\mathrm{X}$ angles are below $120^{\circ}$ for weak hydrogen bonds. The C-H(thiazolic)--- $\mathrm{Cl}$ in the chloroaryl thiazole, III, is $117.64^{\circ}$. The stabilization energy due to intramolecular hydrogen bonding was estimated by the comparison of the energy between the conformer that forms the hydrogen bond and the conformer that lacks it. With a $90^{\circ}$ rotation between the two aromatic rings, the energetic difference found for compound III is $\Delta \mathrm{E}=3.78 \mathrm{kcal} / \mathrm{mol}$, calculated by B3LYP/6-31G*/ECP. With a $180^{\circ}$ rotation, the energetic difference is $\Delta \mathrm{E}=5.94 \mathrm{kcal} / \mathrm{mol}$. In the last conformer there is electric repulsion between the chlorine and the nitrogen atoms.

Other calculations have been done[19], but the present study is devoted to find, or not, the bond critical points due to hydrogen bonding, thus clearing the subject.

For the organic preparations see[20].

\section{Conclusions}

In our compounds 1 and $3, \mathrm{C}-\mathrm{H}---\mathrm{O}$ and $\mathrm{C}-\mathrm{H}---\mathrm{Cl}$ interactions originate bond critical points and there is agreement with the hydrogen-bond criteria. On the other hand, the C-H---N interactions found by ${ }^{1} \mathrm{H}$ NMR in the same compounds, did not originate bond critical points and are only in partial agreement with hydrogen-bond criteria. These special interactions maybe could be named 'semibonds'.

\section{REFERENCES}

[1] Ibon Alkorta, Jose Elguero, "Non- conventional Hydrogen Bonds", Royal Society of Chemistry, Chemical Society Reviews, vol. 27, no. 2, pp. 163-170, 1998. 
[2] George A. Jeffrey, An Introduction to Hydrogen Bonding, Oxford University Press, New York, USA, 1997, pp. 85, 228.

[3] Gautam R. Desiraju, Thomas Steiner, The Weak Hydrogen Bond, Oxford University Press, Oxford, UK, 1999.

[4] Francisco Sanchez-Viesca, Martha Berros, "1H NMR Evidence of C-H---O, C-H---N and C-H---Cl Hydrogen Bonds in New Thiazole Derivatives", Elsevier, Heterocycles, vol. 57, no. 10, pp.1869-1879, 2002.

[5] Axel D. Becke, "Density Functional Thermochemistry. III. The Role of Exact Exchange", American Institute of Physics, The Journal of Chemical Physics A, vol. 98, no. 7, pp. 5648-5652, 1993

[6] Mark S. Gordon, "The Isomers of Silacyclopropane", Elsevier, Chemical Physics Letters, vol. 76, no. 1, pp. 163-168, 1980.

[7] Michael J. Frisch, John A. Pople, J. Stephen Binkley, "Self Consistent Molecular Orbital Methods 25. Supplementary Functions for Gaussian Basis Sets", American Institute of Physics, The Journal of Chemical Physics, vol. 80, no. 7, pp. 3265-3269, 1984

[8] Michael J. Frisch et al., Gaussian 03, Revision C.02, Gaussian Inc., Wallingford, CT, USA, 2004.

[9] Friedrich Biegler-König, J. Schönbohm, D. Bayles, "AIM2000-A Program to Analyze and Visualize Atoms in Molecules", Wiley Periodicals, Journal of Computational Chemistry, vol. 22, no. 5, pp. 545-559, 2001.

[10] Richard F. W. Bader, "A Bond Path: A Universal Indicator of Bonded Interactions", American Chemical Society, Journal of Physical Chemistry A, vol. 102, no. 37, pp. 7314-7323, 1998.

[11] Jerzy Cioslowski, Stacey T. Mixon, "Universality Among Topological Properties of Electron Density Associated with the Hydrogen-hydrogen Nonbonding Interactions", NRC Research Press, Canadian Journal of Chemistry, vol. 70, no. 2, pp. 443-449, 1992.

[12] Sylvain Bernes, Martha Berros, Cecilia Rodriguez, Francisco Sanchez-Viesca, "Flat versus Twisted Rotamers of
2,4-Disubstituted Thiazoles", International Union of Crystallography, Acta Crystallographica C, vol. 58, pp. o151-o153, 2002.

[13] I. V. Tselinskii, P. B. Levit, V. A. Shlyapochnikov, "Geometry of Molecular Biphenyl Derivatives", Akademiia Nauk SSSR, Zhurnal Obshchei Khimii, vol. 62, no. 1, pp. 173-181, 1992. English version: Consultants Bureau, NY, Journal of General Chemistry of the USSR, vol. 62, no. 1, pp. 142-148, 1992

[14] U. Koch, P. L. A. Popelier, "Characterization of C-H-O Hydrogen Bonds on the Basis of the Charge Density", American Chemical Society, Journal of Physical Chemistry, vol. 99, no. 24, pp. 9747-9754, 1995.

[15] P. L. A. Popelier, "Characterization of a Dihydrogen Bond on the Basis of the Electron Density", American Chemical Society, Journal of Physical Chemistry A, vol. 102, no. 10, pp. 1873-1878, 1998.

[16] Gabriel Cuevas, "Hydrogen Bond Type Contributions to the Anomeric Effect in S-C-P(O) and S-C-P(S) Segments", American Chemical Society, Journal of the American Chemical Society, vol. 122, no. 4, pp. 692-698, 2000.

[17] Richard F. W. Bader, Atoms in Molecules. A Quantum Theory, Clarendon, Oxford, UK, 1990.

[18] Robin Taylor, Olga Kennard, "Crystallographic Evidence for the Existence of C-H---O, C-H---N and C-H---Cl Hydrogen Bonds", American Chemical Society, Journal of the American Chemical Society, vol. 104, no. 19, pp. 5063-5070, 1982.

[19] Miguel Castro, Ines Nicolas, Jesus Zavala, Francisco Sanchez-Viesca, Martha Berros, "Theoretical Study of Intramolecular, $\mathrm{CH}-\mathrm{X}(\mathrm{X}=\mathrm{N}, \mathrm{O}, \mathrm{Cl})$, Hydrogen Bonds in Thiazole Derivatives", American Chemical Society, Journal of Chemical Theory and Computation, vol. 3, no. 3, pp. 681-688, 2007.

[20] Francisco Sanchez-Viesca, Martha Berros, "Synthesis and Rotamerism of New Polysubstituted 4-Arylthiazoles", Laboratorios Mixim, Revista Latinoamericana de Quimica, vol. 27 , no. 1 , pp. 26-32, 1999. 